\title{
A novel translational repressor mRNA is edited extensively in livers containing tumors caused by the transgene expression of the apoB mRNA-editing enzyme
}

\author{
Shinya Yamanaka, ${ }^{1}$ Karen S. Poksay, ${ }^{2}$ Kay S. Arnold, ${ }^{2}$ and Thomas L. Innerarity ${ }^{2-5}$ \\ ${ }^{2}$ Gladstone Institute of Cardiovascular Disease, ${ }^{3}$ Cardiovascular Research Institute, and ${ }^{4}$ Department of Pathology, \\ University of California, San Francisco, California 94141-9100 USA
}

\begin{abstract}
Transgene expression of the apolipoprotein B mRNA-editing enzyme (APOBEC-1) causes dysplasia and carcinoma in mouse and rabbit livers. Using a modified differential display technique, we identified a novel mRNA (NAT1 for novel APOBEC-1 target no. 1) that is extensively edited at multiple sites in these livers. The aberrant editing alters encoded amino acids, creates stop codons, and results in markedly reduced levels of the NAT1 protein in transgenic mouse livers. NAT1 is expressed ubiquitously and is extraordinarily conserved among species. It has homology to the carboxy-terminal portion of the eukaryotic translation initiation factor (eIF) $4 \mathrm{G}$ that binds eIF4A and eIF4E to form eIF4F. NAT1 binds eIF4A but not eIF4E and inhibits both cap-dependent and cap-independent translation. NAT1 is likely to be a fundamental translational repressor, and its aberrant editing could contribute to the potent oncogenesis induced by overexpression of APOBEC-1.
\end{abstract}

[Key Words: APOBEC-1; RNA editing; translation repressor; transgenic mice]

Received October 28, 1996; revised version accepted December 18, 1996.

Apolipoprotein $\mathrm{B}(\mathrm{apoB})$ mRNA editing is the deamination of a specific cytidine (nucleotide 6666) to form uridine in the 14-kb apoB mRNA (Chen et al. 1987; Powell et al. 1987). This deamination changes a glutamine codon (CAA) to a translation termination codon (UAA) and results in the formation of an apoB protein (apoB48) consisting of the amino-terminal $48 \%$ of the full-length genomically encoded apoB (apoB100) (Scott 1995; Innerarity et al. 1996). ApoB mRNA is edited in the small intestines of mammalian species as well as in the livers of some mammals such as mice and rats (Greeve et al. 1993). The enzyme APOBEC-1 (apoB mRNA-editing catalytic subunit polypeptide 1) that catalyzes the cytidine deamination has been cloned (Teng et al. 1993). APOBEC-1 possesses RNA-binding activity (Anant et al. 1995; Navaratnam et al. 1995) and cytidine deaminase activity (Navaratnam et al. 1993) but is inactive without the addition of protein extracts that presumably contain missing auxiliary or complementary factors necessary for editing. These unidentified auxiliary proteins are widely but not ubiquitously distributed in many organs

\footnotetext{
${ }^{1}$ Present address: Department of Pharmacology, Osaka City University Medical School, Osaka 545, Japan.

${ }^{5}$ Corresponding author.

E-MAIL tom_innerarity@quickmail.ucsf.edu; FAX (415) 285-5632.
}

and tissues (Driscoll and Zhang 1994; Giannoni et al. 1994; Yamanaka et al. 1994). Thus, APOBEC-1 appears to be part of a multiprotein complex (Harris et al. 1993; Giannoni et al. 1994).

Quite unexpectedly, we found that the overexpression of APOBEC-1 causes dysplasia and hepatocellular carcinoma in transgenic mouse livers (Yamanaka et al. 1995). It also induced hepatic dysplasia in a transgenic rabbit founder. Overexpression of APOBEC-1 resulted in the development of hepatocellular carcinoma as early as 21 days after birth in transgenic mice. This potent oncogenesis was not attributable to transforming elements in the vector, insertion effects of transgenes, or the increased formation of the apoB48 protein. We hypothesized that the oncogenesis is a result of the aberrant editing of other mRNA(s) encoding protein(s) with important cellular function(s). If this hypothesis is correct, the identification of other target mRNAs of overexpressed APOBEC-1 could lead to the discovery of molecules important in regulating cell growth.

To identify other targets of APOBEC-1, we initially took a candidate mRNA approach (Yamanaka et al. 1995, 1996). Mutagenesis studies suggested that the sequence specificity of apoB mRNA editing is provided by a mooring sequence-an 11-nucleotide sequence motif located five nucleotides downstream from the edited cytidine $\left(C^{6666}\right)$ in apoB mRNA (Shah et al. 1991; Backus et al. 
1994). In vitro, the mooring sequence was sufficient to induce editing of cytidines four to six nucleotides upstream in chimeric RNA (Driscoll et al. 1993; Backus and Smith 1994). We searched genomic databases for other mRNAs containing the mooring sequence and found six mRNA candidates that have a mooring-like sequence as well as cytidines four to six nucleotides upstream. The upstream cytidines of these mRNAs were examined for editing. In the APOBEC-1 transgenic mouse livers, only one of these six candidates [a tyrosine kinase mRNA (Mano et al. 1990)] showed detectable editing $(\sim 1 \%)$, which did not change the encoded amino acid. No cytidines in any of the six candidate mRNAs were edited in control mouse livers. This candidate approach suggests that the pathological editing by overexpressed APOBEC-1 remains selective and requires other unidentified element(s) in addition to the mooring sequence. It became apparent that better approaches would be required to identify other target mRNAs, especially those that are not in the genomic databases.

In this study, we used a modified differential display technique (Liang and Pardee 1992) to search for edited mRNAs. We identified, cloned, and characterized a novel mRNA that is extensively edited in transgenic mouse and rabbit livers. This mRNA, NAT1 (novel APOBEC-1 target 1), encodes a protein that appears to be involved in the regulation of translation initiation. In addition, comparison of apoB mRNA and NAT1 sequences gave us new insights into the mechanism of APOBEC-1-mediated mRNA editing.

\section{Results}

\section{Identification of NAT1}

We modified the differential display technique to selectively amplify mRNAs that were edited in the livers of transgenic mice overexpressing APOBEC-1. Primers (mooring primers) were designed that consisted of a sequence complementary to the mooring sequence, three to five degenerate nucleotides, and an adenosine at the $3^{\prime}$ end (Fig. 1A). Cytidines four to six nucleotides upstream of the mooring sequence can be edited in vitro (Driscoll et al. 1993; Backus and Smith 1994). These mooring primers served as antisense primers for cDNA synthesis and PCR instead of the anchored oligo-dT primers usually used in the differential display procedure (Liang and Pardee 1992). Using this modified technique, we identified differentially amplified bands on agarose gels (Fig. 1B) from which DNAs were eluted, subcloned, and sequenced. A search of genomic databases revealed that two of the three clones shown in Figure 1B (clones 3-13 and 3-13') were nearly identical to each other and to several human expressed sequence tags (ESTs) (Adams et al. 1992). Importantly, the mouse sequences derived from the modified differential display had thymidines in place of several cytidines in the human EST sequences, suggesting that these cytidines may be edited in the transgenic mice expressing APOBEC-1. To confirm this observation, we designed primers based on the human sequence and amplified the 92-bp sequence from control mouse liver RNA, transgenic mouse liver RNA, and mouse genomic DNA. When sequenced, the PCR products from control mouse liver RNA and the genomic DNA were identical to the human sequence. In contrast, the PCR products from the APOBEC- 1 transgenic mouse liver RNA had thymidines in the place of several cytidines, as in the DNA from differential display, further suggesting that these cytidines are edited in the transgenic mouse livers. Primer extension analysis also confirmed the editing of multiple cytidines in both transgenic mouse livers and in the transgenic rabbit founder that overexpressed rabbit APOBEC-1 in their livers and developed severe hepatic dysplasia (Fig. 1C). This mRNA has been designated NAT1.

Northern blot analyses revealed that NAT1 is expressed at high levels in adult human heart, brain, placenta, lung, liver, skeletal muscle, kidney, and pancreas (Fig. 1D), as well as in spleen, thymus, prostate, testis, ovary, small intestine, colon, and peripheral blood leukocytes (data not shown). NAT1 is also expressed in fetal human brain, lung, liver, and kidney (data not shown). All human cell lines examined expressed NAT1 at approximately the same levels, including HL-60 (promyelocytic leukemia), HeLa S3, K-562 (chronic myelogenous leukemia), MOLT-4 (lymphoblastic leukemia), Raji (Burkitt's lymphoma), SW480 (colorectal adenocarcinoma), A549 (lung carcinoma), and G361 (melanoma) (data not shown). Southern blot analysis (Fig. 1E), in which human EST cDNA was used as a probe under highly stringent conditions, demonstrated that the NAT1 sequence is highly conserved among mammalian species (human, monkey, rat, mouse, dog, bovine, and rabbit). A weaker band present in chicken suggested the existence of a NAT1 homolog in this species. No band was detected in yeast. The high degree of conservation and the ubiquitous distribution of the mRNA suggest that NAT1 has critical functions in cellular physiology.

\section{Cloning of the full-length NAT1 cDNA}

We sequenced the longest clone $(2.4 \mathrm{~kb})$ of five human EST clones derived from NAT1 mRNA. That it was not a full-length clone was revealed when Northern blot analysis demonstrated a 4-kb transcript (Fig. 1D). Using 5'-RACE-PCR (Frohman et al. 1988), we obtained a fulllength cDNA of human NAT1 $(3.8 \mathrm{~kb})$. Mouse and rabbit NAT1 full-length cDNAs were obtained by RT-PCR with primers based on the human sequence (Fig. 2). At the nucleotide level, human and rabbit sequences are $95.5 \%$ and $94.8 \%$ identical, respectively, to the mouse sequences. The $3^{\prime}$ sequence of NAT1 mRNA contains five sequence motifs that are only one or two nucleotides different from the apoB mRNA mooring sequence (Figs. 2 and 4A). The sequence motif in NAT1 recognized by the mooring primer differed by one nucleotide from the apoB mRNA mooring sequence and also had a onenucleotide deletion. NAT1 cDNA contains a single open reading frame of $>2.8 \mathrm{~kb}$, but the first $\mathrm{ATG}$ codon is 
First Strand Synthesis

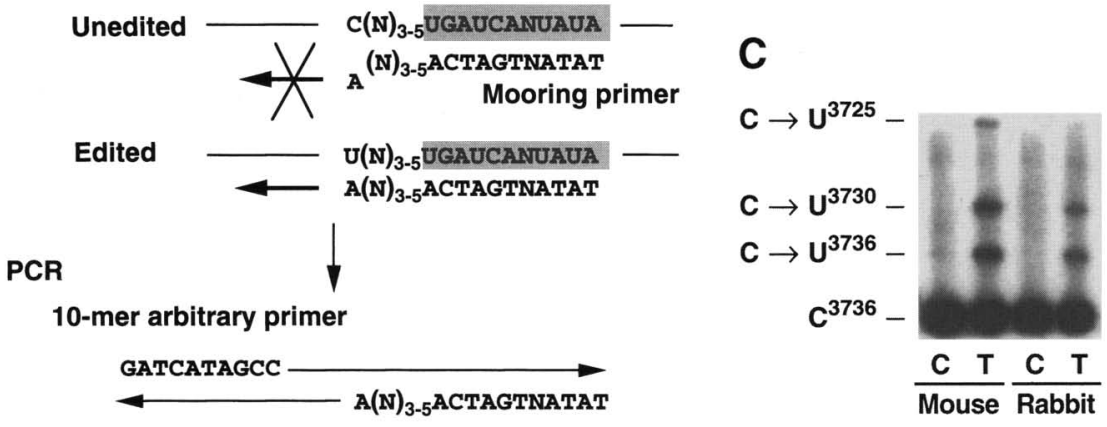

B
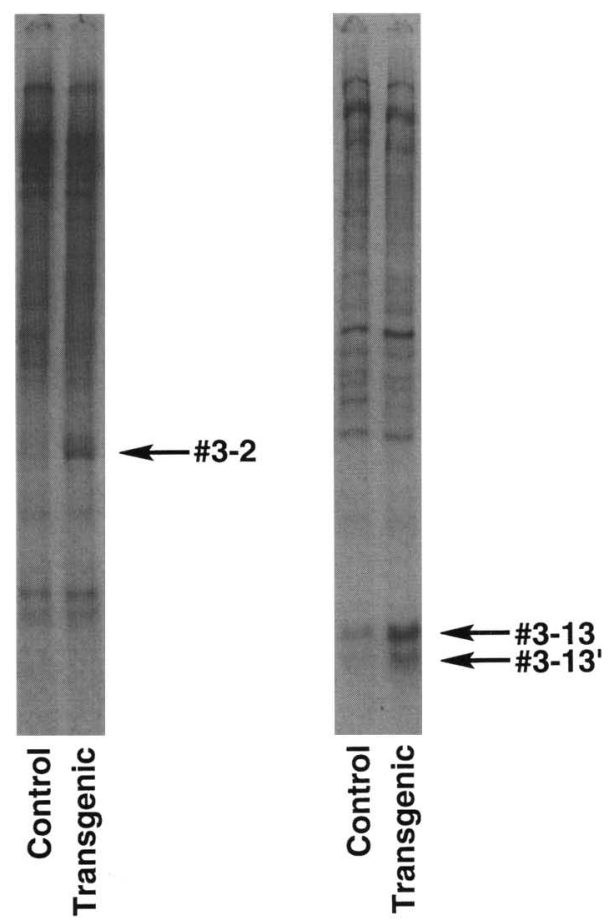
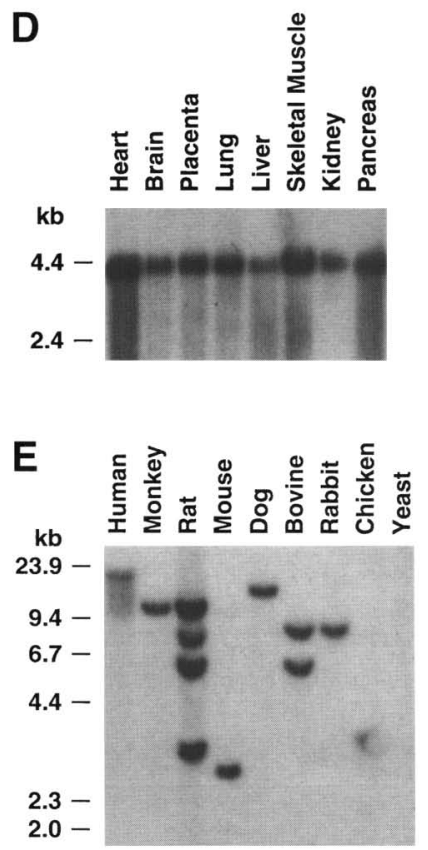

Figure 1. Identification of NAT1. $(A)$ Schematic illustration of a modified differential display procedure to detect edited mRNAs in transgenic mouse livers overexpressing APOBEC-1. (B) Sequencing gel of radioactive products of the modified differential display reaction. The arrows denote RNAs present in higher amounts from transgenic mouse liver than from the control liver. By using 24 different arbitrary primers and three different mooring primers, we obtained three RNAs that were amplified more efficiently in the transgenic mouse livers $(3-2,3-13$, and 3-13'). (C) Primer extension analyses demonstrating multiple edited cytidines from NAT1 mRNA isolated from transgenic mouse and rabbit livers. Extra bands in transgenic cDNA indicate the editing of $\mathrm{C}^{3725}, \mathrm{C}^{3730}$, and $\mathrm{C}^{3736}$. (D) Northern blot analysis of NAT1 showing its ubiquitous expression in various human tissues. $(E)$ Southern blot analysis demonstrates that NAT1 is highly conserved among several species. The DNA was digested with EcoRI. located far downstream at nucleotide 925 and does not reside in a Kozak consensus sequence motif (Kozak 1991). To determine whether this first ATG codon is the translation initiation codon of NAT1, we expressed a NAT1 cDNA by in vitro transcription/translation in the presence of $\left[{ }^{35} \mathrm{~S}\right]$ methionine. If this first ATG codon were the start codon, a protein of $\sim 80 \mathrm{kD}$ would have been expected. Instead, a $100-\mathrm{kD}^{35} \mathrm{~S}$-labeled protein was detected (Figs. 3 and 4B), suggesting that an upstream nonATG codon initiated translation of NAT1.

To identify the translation initiation codon of NAT1, we performed a series of site-directed mutagenesis experiments and transcribed and translated the mutants in vitro (Fig. 3). First we tested 5 '-truncated mutants of NAT1, which demonstrated that the start codon should be in the short sequence consisting of nucleotides 303 324. In this region, a GTG codon at nucleotide 307 and an ATT codon at nucleotide 319 function as initiation codons in other mRNAs (Hann 1994). We mutated these codons to GAG and TTT, respectively. The GTG $\rightarrow$ GAG mutant did not translate into any significant protein products (Fig. 3). In contrast, a $100-\mathrm{kD}$ protein was translated from the ATT $\rightarrow$ TTT mutant. These data demonstrate that the GTG codon at nucleotide 307 is the translation initiation codon of NAT1. From this GTG start codon, the open reading frame of 2718 bases encodes a 906-amino-acid protein with a calculated molecular mass of $102 \mathrm{kD}$, which is consistent with the migration of the protein on SDS-PAGE. Rabbit and human NAT1 open reading frames are $3 \mathrm{bp}$ (one amino acid) longer than that 
gagcagtgagtcggagetctatggaggtgc

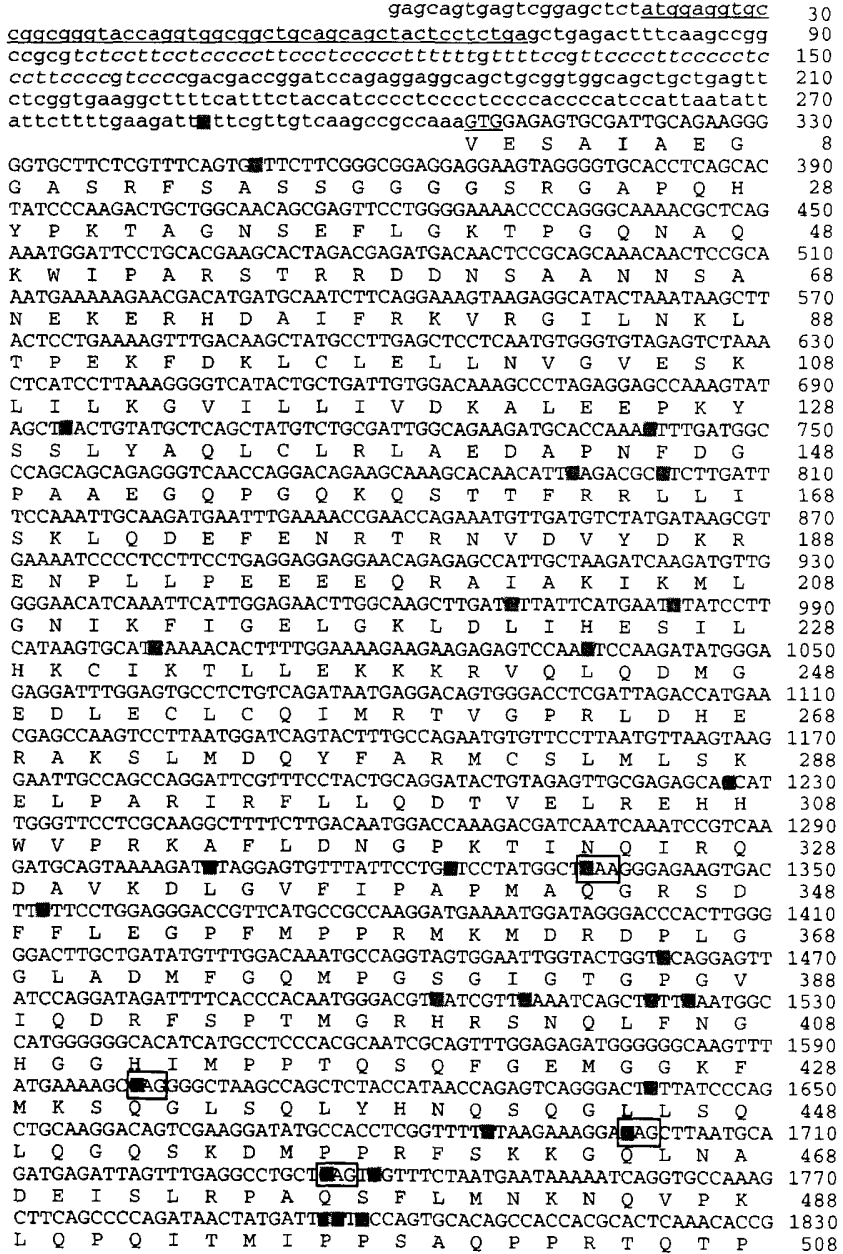

CCTCTGGGACAGACACCTCAACTTGGTCTCAAAACTAATCCAECACTTATCAGGAAAA 1890 \begin{tabular}{lllllllllllllllllllll}
$P$ & $L$ & $G$ & $Q$ & $T$ & $P$ & $Q$ & $L$ & $G$ & $L$ & $K$ & $T$ & $N$ & $P$ & $P$ & $L$ & $I$ & $Q$ & $E$ & $K$ & 528 \\
\hline
\end{tabular}

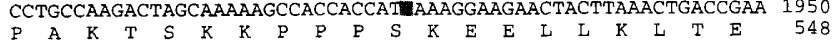

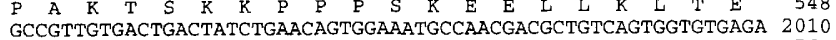

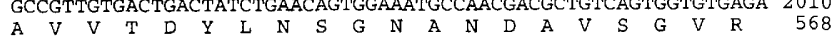
GAAATGAGAGCTCCAAAACA TTT TTCCTGAGATGCTAAGCAAAGTGATCATECTGTCA 2070 $\begin{array}{llllllllllllllllllllll}E & M & R & A & P & K & H & F & \text { L } & P & E & M & L & S & K & V & I & I & L & S & & 588\end{array}$ CTTGATAGAAGTGATGAAGATAAAGAAAAAGCAAGCTCTTTAATCAGTTTACTCAAACAG 2130 $\begin{array}{llllllllllllllllllllll}L & D & R & S & D & E & D & K & E & K & A & S & S & L & I & S & L & L & K & Q & 608\end{array}$ GAAGGGATAGCCACAAGTGACAACTTCATGCAGGCTTTCCTGAATGTATTGGAGCAGTGC 2190 $\begin{array}{lllllllllllllllllllll}E & G & I & A & T & S & D & N & F & M & Q & A & F & L & N & V & L & E & Q & C & 628\end{array}$

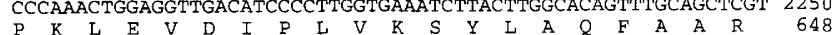

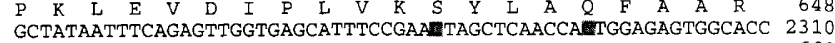
$\begin{array}{llllllllllllllll}\text { A I I S S E L V S } & \text { S } & \text { S } & \text { E } & \text { L } & \text { A } & \text { Q } & \text { P } & \text { L } & \text { E } & \text { S } & G & \text { T } & 668\end{array}$ CACTTCCCTCTCTI TTACTTTG TAACAATAGCTAAATTGCAAGACCGAGAGTGG 2370

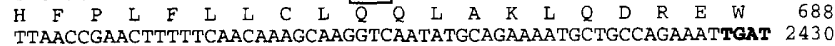
TTAACCGAACTTTTTCAACAAAGCAAGGTCAATATGCAGAAAATGCTGCCAGAAATTGAT 2430

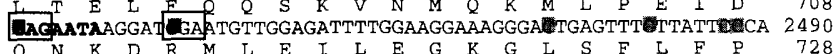

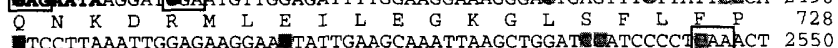

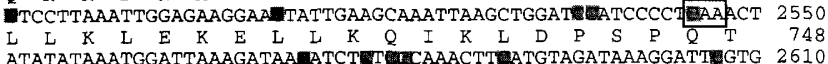

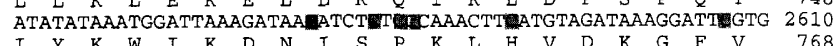

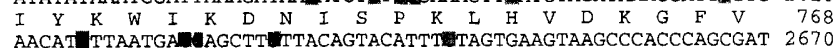

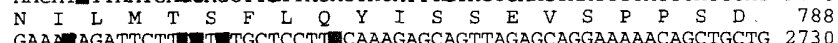
GAAA AGATTCTTWTITGCTCCTICAAAGAGCAGT TAGAGCAGGAAAACACCTGCTG 2730 CTCTCTTTTAAGCCAGTGATGCAGAAATT" $\begin{array}{lllllllllllllllllllll}\text { L } & S & F & K & P & V & M & Q & K & F & L & H & D & H & V & D & L & Q & V & S & 828\end{array}$ $\begin{array}{lllllllllllllllllllll}\text { A } & L & Y & A & F & Q & V & H & C & Y & N & S & S & F & P & K & G & M & L & L & 848\end{array}$ CGATTTTTGTT ACTT TATGACATGGAAATATTGAAGAGGAGCTTTCTTAGCTTGG 2910

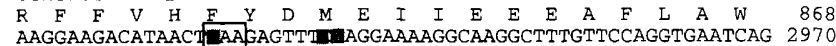

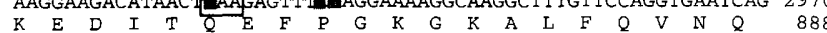
TGGCTAACCTGGCTAGAAATGCTGAAGAAGAAGAATCAGAGGAAGAAGCTGACtaaaga 3030

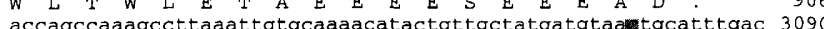
accagccaaagccttaaattgtgcaaaacatactgttgctatgatgtaatgcatttgac 3090 ctaacca tgcgaaatt att gctg taal acgt agtaaggtttmttrgcataaggtttt tgtagtgtgatgt taatcatagt 3210 cat aaata tt taggagtat nttaatgtttagatagaatattagcagcatgcaata 3270

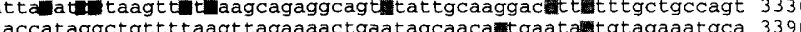
taccataggctgttttaagttagaaactgaatagcaaca cttgct agtaatacttgagttgttgcaatattgattat catttggttgttalagaa 3450 aat ttaaltgtaattgatggttgttgccgtaatagtatattgcctgtattcta 3510

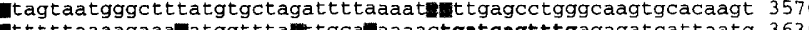
ttttaaaagaamatggtttant tgcalaaactgatcagtttgagagatcattaatg 3630 ccttgaagtggtttttgtgggtgtgaaacaatggtgagaatttgaattggt潇ctctt 3690

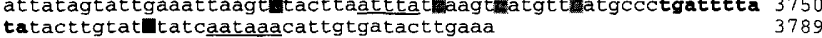

Figure 2. Complementary DNA and predicted amino acid sequences of mouse NAT1. The GTG translation initiation codon determined by the experiments shown in Fig. 3 is underlined. An upstream openreading frame in the $5^{\prime}$ UTR, a polyadenylation signal (AATAAA), and destabilizing elements (ATTTA) in the $3^{\prime}$ UTR are also underlined. Polypyrimidine tracts in the $5^{\prime}$ UTR are italicized. Five sequence motifs that differ by one or two nucleotides from the apoB mRNA mooring sequence (TGATCANTATA) are indicated by boldface type. The edited cytidines are shaded. Codons that are changed to stop codons by editing are boxed. Bands 3-13, 3-13' correspond to the sequence $3673-3751$ of NAT1.

of the mouse sequence. The predicted amino acid sequence is $98.2 \%$ identical among the mouse, human, and rabbit proteins. The 5 - untranslated region (UTR) is relatively long (306 bases) and contains an upstream open reading frame and polypyrimidine tracts. The $3^{\prime}$ UTR is also relatively long (757 bases) and AU-rich $(65.6 \%)$ and contains an AUUUA destabilizing element (Greenberg and Belasco 1993). In addition, both UTRs are highly conserved among the three species $\left(5^{\prime}\right.$ UTR, $90.1 \%$; $3^{\prime}$ UTR, $95.5 \%$ ). These features suggest that the UTRs may have regulatory functions, such as controlling translation and/or mRNA stability.

\section{Hyperediting of NAT1}

The mRNA sequence found to be edited by the modified differential display was located in the $3^{\prime}$ end of the fulllength NAT1. To determine whether cytidines in the other parts of the full-length NAT1 mRNA were also edited, we sequenced multiple cDNA clones from control and transgenic mouse liver RNA. Surprisingly, more than 100 cytidines throughout the entire sequence of NATl were edited in transgenic mouse livers (Figs. 2 and 4A). We designated this aberrant editing as hyperediting to distinguish it from normal editing, which modifies only one cytidine in the apoB mRNA. The frequency of the hyperediting at each cytidine ranged from $4 \%(1 / 23$ clones) to $71 \%$ (5/7 clones) (Fig. 4A). Cytidines in the $3^{\prime}$ half of NAT1, where mooring-like sequences are clustered, are edited preferentially (Fig. 4A). Most of the same cytidines were edited in the liver of the transgenic founder rabbit overexpressing APOBEC-1 (data not shown|.

The hyperediting of multiple cytidines was predicted to alter the encoded amino acids and create multiple stop codons. To confirm the creation of multiple stop codons, we expressed multiple cDNA clones of NAT1 from control and transgenic mouse livers by in vitro transcrip- 


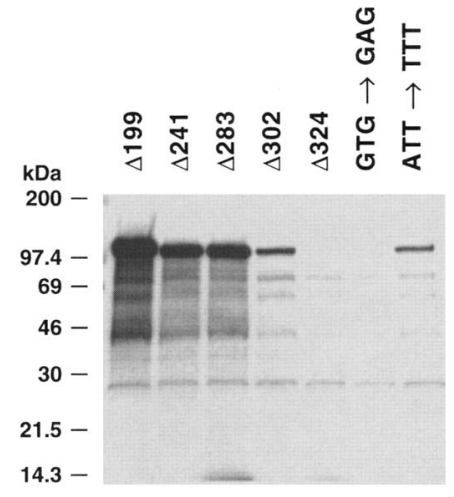

Figure 3. Identification of the translation initiation codon of NAT1. Sequential 5'-deletion mutants $(\Delta 199, \Delta 241, \Delta 283$, $\Delta 302, \Delta 324$ ) and substitution mutants (GTG $\rightarrow$ GAG, ATT $\rightarrow$ TTT) were expressed by in vitro transcription and translation in the presence of $\left[{ }^{35} \mathrm{~S}\right]$ methionine. Shown is an autoradiograph of the labeled protein separated by SDS-PAGE.

tion/translation in the presence of $\left[{ }^{35} \mathrm{~S}\right]$ methionine. All four cDNA clones from the control mouse liver generated proteins migrating with an apparent molecular mass of $100 \mathrm{kD}$ (Fig. 4B), which is consistent with the calculated molecular mass of NAT1. In contrast, four of five cDNAs from a transgenic mouse liver produced truncated proteins of various sizes, indicating that a stop codon had been generated at a different site in each clone.

To study the pathophysiological impact of hyperediting, we generated a polyclonal antibody against a fragment of NAT1 (amino acids 369-490) for use in Western blot analysis of protein extracts from control and transgenic mouse livers. In the control mouse liver extract, the antibody recognized a protein with an apparent molecular mass of $100 \mathrm{kD}$ (Fig. 4C). Although control and transgenic mouse livers had similar NAT1 mRNA levels (data not shown), the concentration of this protein was markedly reduced in transgenic mouse livers. Thus, the reduced NAT1 protein levels in transgenic mouse liver extracts probably result from the creation of multiple premature stop codons. Alternatively, hyperediting in the 3' UTR may have decreased the translation efficiency of NAT1.

The normal apoB mRNA editing requires auxiliary protein(s) in addition to APOBEC-1 (Driscoll and Zhang 1994; Giannoni et al. 1994; Yamanaka et al. 1994). To determine whether the hyperediting of NAT1 also requires auxiliary protein(s), we synthesized NAT1 RNA by in vitro transcription from full-length cDNA and incubated the RNA with recombinant APOBEC-1 either alone or with extracts from normal rabbit liver containing auxiliary proteins but no APOBEC-1. Primer extension analyses demonstrated hyperediting of NATl only in the presence of the auxiliary proteins (Fig. 4D). Thus, hyperediting of NAT1 by overexpressed APOBEC-1 requires auxiliary proteins.
Function of NAT1

A database search using the BLAST network service at the National Center for Biotechnology Information revealed that NAT1 is similar to the eukaryotic translation initiation factor (eIF) 4G, which is essential for the cap-dependent translation initiation of cellular RNA (Hershey 1991; Merrick 1992; Thach 1992; Rhoads 1993). NAT1 has $20-69 \%$ amino acid identity with human eIF4G (Yan et al. 1992), the wheat isoform p80 (Allen et al. 1992), and the yeast homolog p150 (Goyer et al. 1993) (Fig. 5A). The initiation factor eIF4G binds two additional subunits, eIF4E and eIF4A, to form the ternary cap-binding complex eIF4F. In cap-dependent translation initiation, a cap-binding protein (eIF4E) recognizes the mRNA cap structure, and an RNA helicase (eIF4A) unwinds secondary structures in the $5^{\prime}$ UTR to make the mRNA accessible to ribosomes. The eIF4G subunit connects these two important functions and is crucial for initiating cap-dependent translation. Picornaviruses reduce the cap-dependent translation of host mRNA by producing proteases that cleave eIF4G at amino acid 478 (Lamphear et al. 1993) into an amino-terminal portion containing the eIF4E binding site (Mader et al. 1995) and a carboxy-terminal portion containing the eIF4A binding site (Lamphear et al. 1995). The cleaved carboxy-terminal domain is sufficient to maintain the cap-independent and internal ribosome entry site (IRES)-dependent translation initiation of viral RNA (Lamphear et al. 1995; Ohlmann et al. 1996). Importantly, some cellular mRNAs are translated by the cap-independent, IRES-dependent mechanism (Teerink et al. 1995; Vagner et al. 1995; Gan and Rhoads 1996).

Because NAT1 has apparent homology to the carboxyterminal domain of eIF4G, we considered the possibility that NATl would bind eIF4A and function in the capindependent translation of cellular RNA. To test this hypothesis, we first used the yeast two-hybrid system to study protein-protein interactions between NATl and eIF4A or eIF4E. NAT1 cDNA was subcloned into pGBT9 plasmid to generate a fusion protein with the DNA-binding domain of GAL4 transcription activator (pGBT9NAT1). Also, eIF4A (Nielsen et al. 1985) or eIF4E (Jaramillo et al. 1991b) was subcloned into pGAD424 plasmids to generate fusion proteins with the GAL4 activation domain (pGAD424-4A and pGAD424-4E, respectively). pGBT9-NAT1 was cotransformed with either pGAD424 (control), pGAD424-4A, or pGAD424-4E into yeast that has the lac $Z$ reporter gene containing upstream GAL4-binding sites. In the yeast cotransformed with NAT1 and eIF4A, lacZ was activated (Fig. $5 B$ ). In contrast, $1 a c Z$ was not activated in the yeast cotransformed with NAT1 and either control or eIF4E. These results indicate that NAT1 binds eIF4A but not eIF4E, as would be expected from its sequence similarity with the carboxy-terminal portion of eIF4G.

To examine the impact of NAT1 on protein translation, we generated a bicistronic reporter gene in which the first cistron, chloramphenicol acetyltransferase (CAT), is translated by a cap-dependent mechanism and 
Figure 4. In vitro and in vivo hyperediting of NAT1. (A) Distribution of edited cytidines in NAT1 mRNA from transgenic mouse livers. Seven to $23 \mathrm{cDNA}$ clones of NAT1 from transgenic mouse livers were sequenced to determine the extent of cytidine editing at each position. Arrows indicate the positions of the five mooring-like sequences. $(B)$ Impact of the hyperediting in vitro. Multiple cDNA clones of NAT1 obtained by RT-PCR from control and transgenic mouse liver RNA were transcribed and translated in vitro in the presence of $\left[{ }^{35} \mathrm{~S}\right]$ methionine. $(C)$ Western blot of NAT1 in S100 extracts from three control and three APOBEC-1 transgenic mouse livers using a polyclonal antibody generated against a fragment of NATl corresponding to amino acids 369-490. (D) In vitro editing of NAT1. NATl RNA was transcribed in vitro and incubated with recombinant APOBEC-1 either alone or with rabbit liver extracts containing auxiliary proteins. In vitro editing was detected by primer extension analysis.
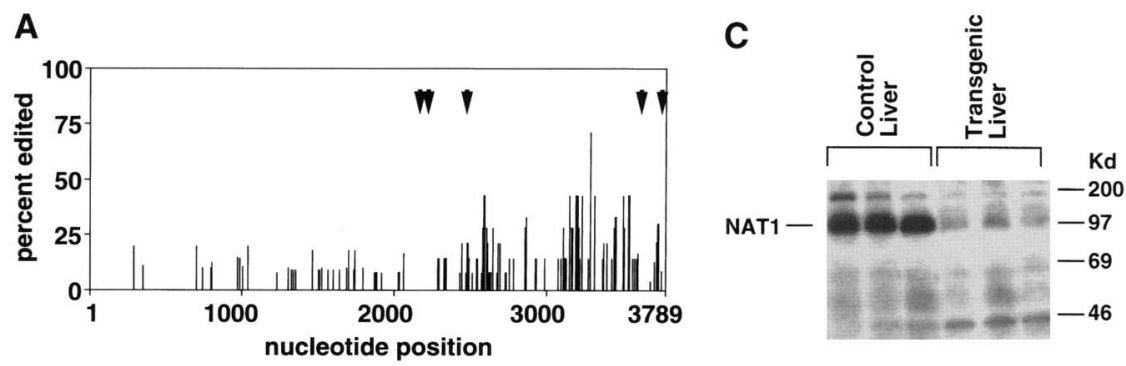

B

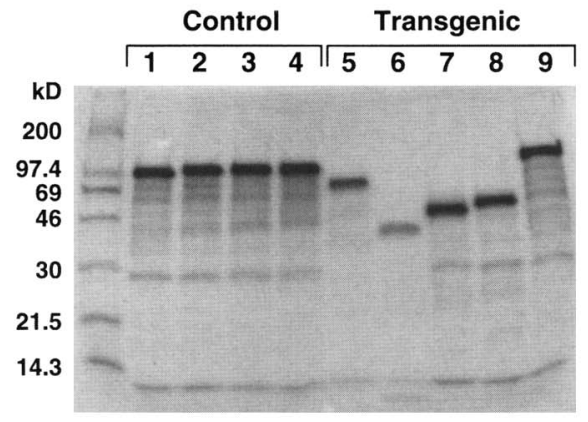

the second cistron, luciferase, is translated by a cap-independent (IRES-dependent) mechanism (Fig. 5C). This bicistronic construct was transiently cotransfected into COS7 cells with either a control vector, a vector encoding the carboxy-terminal fragment of eIF4G (corresponding to amino acids 477-1396), or a vector encoding NAT1. Seventy-two hours after the transfection, CAT activity, luciferase activity, and the mRNA concentrations of the reporter genes were measured. Cap-dependent translation efficiency was estimated as CAT activity divided by the mRNA concentration, and cap-independent translation efficiency as luciferase activity divided by the mRNA concentration. Cotransfection with the carboxy-terminal fragment of eIF4G markedly enhanced cap-independent translation of luciferase (Fig. 5D), which confirmed the previous work of Lamphear et al. (1995) and Ohlmann et al. (1996) and indicated that COS7 cells are a valid system to study translation initiation. Surprisingly, NAT1 inhibited the cap-independent translation of luciferase by $45 \%$. Both the carboxyterminal portion of eIF4G and NAT1 inhibited the capdependent translation of CAT by $40 \%$ (Fig. 5D). These results suggest that NAT1 represses both cap-dependent and cap-independent translation initiation.

\section{Chromosomal localization of the human NAT1 gene}

The sequence similarity between NAT1 and IF4G suggests that they may have been produced by gene duplication. To study this possibility, we obtained a Pl clone containing the human NAT1 gene and determined its chromosomal localization in the human genome. Fluorescence in situ hybridization with the P1 DNA as a probe localized the NAT1 gene to chromosome $11 \mathrm{p} 15$ (data not shown). In contrast, the human IF4G gene was mapped to chromosome 3q27-qtr (Yan and Rhoads 1995). Thus, it is unlikely that the NAT1 gene arose from eIF4G gene duplication.

\section{Discussion}

\section{NAT1 as a fundamental repressor of translation initiation}

Translational control is an important determinant of cell proliferation, differentiation, and development (Sonenberg 1996). In this study, we identified a novel protein, NAT1, that is ubiquitously expressed and extraordinarily conserved among mammalian species. When cotransfected into COS7 cells, NAT1 inhibited both cap-dependent and cap-independent translation of a bicistronic reporter gene. Sonenberg and colleagues (pers. comm.) independently cloned an identical protein, designated p97. When it was cotransfected into HeLa cells along with a bicistronic reporter gene, p97 inhibited cap-dependent and cap-independent translation. When expressed in HeLa cells, p97 also inhibited total protein synthesis as measured by $\left[{ }^{35} \mathrm{~S}\right]$ methionine incorporation. These results taken together indicate that NAT1 (p97) is a fundamental translational repressor.

Cellular mRNA translation initiation is dependent on the $\mathrm{m}^{7} \mathrm{G}$ cap-binding ternary complex eIF4F (Hershey 1991; Merrick 1992; Thach 1992; Rhoads 1993). The subunits of eIF4F are eIF4E, eIF4A, and eIF4G. The eIF4E subunit is required for cap recognition, whereas eIF4A is an RNA helicase required to unwind the secondary structure of the $5^{\prime}$ UTR. These two events are essential for cap-dependent translation initiation. The biochemical function of eIF4G is unknown, but it binds both eIF4A and eIF4E and thus serves as a scaffold to connect these two important proteins in the cap-dependent trans- 


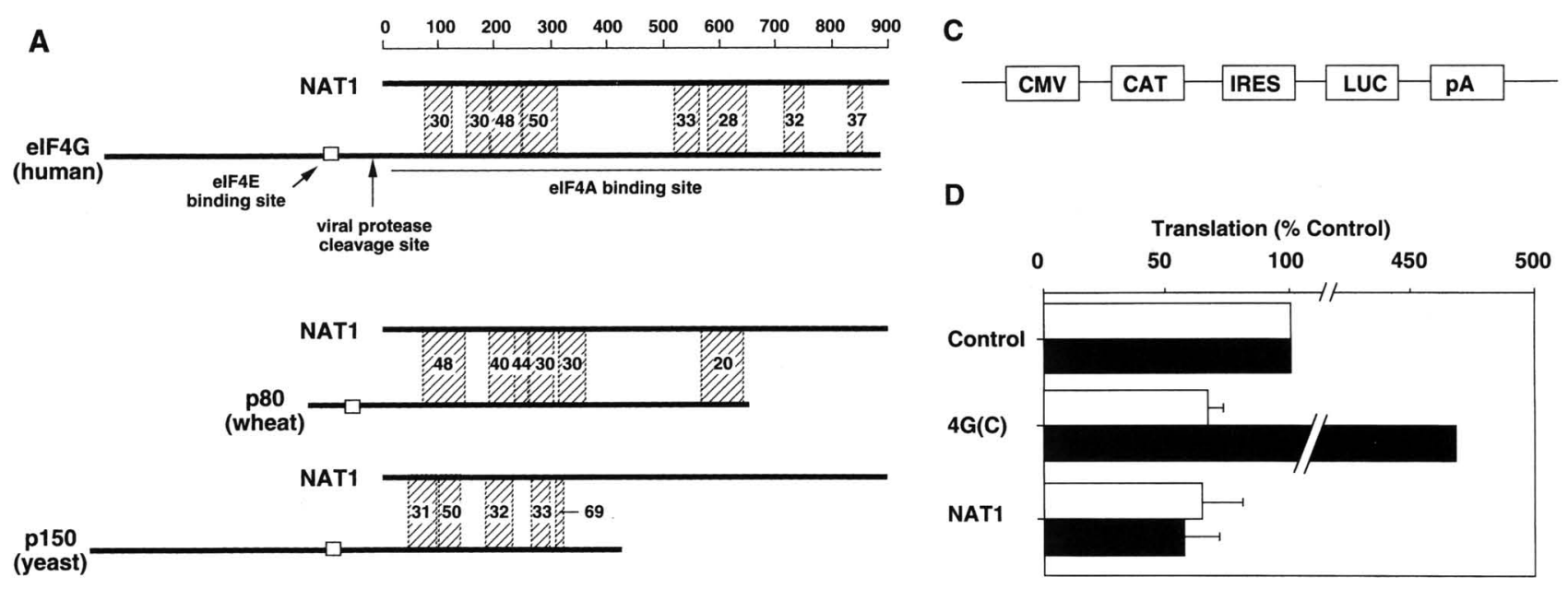

B

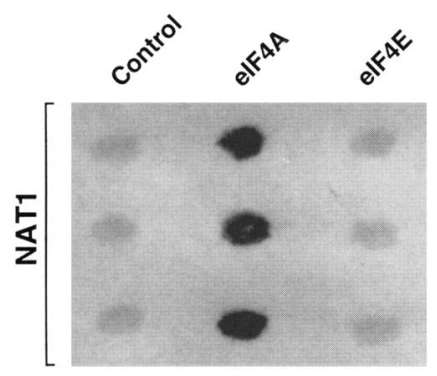

Figure 5. Function of NAT1 in translation. (A) Sequence comparison of NAT1 and eIF4G. The BLAST program was used to compare the predicted amino acid sequence of NAT1 with the sequences of human eIF4G, wheat P80 [eIF(iso)4G], and yeast eIF4G homolog P150. NAT1 is similar to the carboxy-terminal portion of eIF4G and lacks the eIF4E binding site. The shaded boxes represent percent amino acid identity as determined by a BLAST search (Altschul et al. 1990). (B) Yeast two-hybrid system showing the interaction between NAT1 and eIF4A and not eIF4E. pGBT9-NAT1 (a fusion between GAL4 DNA-binding domain and NAT1) was cotransfected into yeast SYF526 with either pGAD424 (GAL activation domain), pGAD424-4A (a fusion of the activating domain and mouse eIF4A), or pGAD424-4E (a fusion of the activating domain and mouse eIF4E). Only the combination of pGBT9-NAT1 and pGAD424-4A activated lacZ, demonstrating the specific binding between eIF4A and NAT1. (C) Bicistronic reporter gene. cDNAs of two reporter genes, CAT, and luciferase (LUC), are located between a single promoter from the immediate early gene of the human cytomegalovirus (CMV) and a polyadenylation signal (pA) from bovine growth hormone. IRES from encephalomyocarditis virus was inserted between the two cDNAs, allowing the capindependent translation of the second cistron, luciferase. The first cistron, CAT, is translated by the cap-dependent mechanism. (D) Effect of NAT1 and the carboxy-terminal fragment of eIF4G on translation. The bicistronic reporter gene was cotransfected into COS7 cells with either pcDNA3.1 (Control), pFlag4G(C) for the expression of the carboxy-terminal fragment of eIF4G [4G(C)], or pcDNAhNAT1 for the expression of human NAT1 (NAT1). (Open bars) Cap dependent; (solid bars) cap independent. The translation efficiency was determined as described in Materials and Methods. Values are shown as percent control and are averages of six experiments for NAT1 and two experiments for the carboxy-terminal fragment of eIF4G.

lation initiation of cellular mRNA. eIF4G also has an affinity for eIF3, which is present on the 40S ribosomal subunit and therefore helps localize the cap-binding translation initiation complex to the ribosomes. Picornaviruses produce proteases that cleave eIF4G into an amino-terminal domain containing the eIF4E binding site (Mader et al. 1995) and a carboxy-terminal portion containing the eIF4A and eIF3 binding sites (Lamphear et al. 1993). This cleavage disrupts the ability of eIF4F to bind the $\mathrm{m}^{7} \mathrm{G}$ cap and thus reduces host mRNA translation. In contrast, the cleaved carboxy-terminal portion of eIF4G, which still binds eIF4A, is sufficient to support the cap-independent (IRES-dependent) translation initiation of viral RNA (Lamphear et al. 1995; Ohlmann et al. 1996).

Because NATl is similar to the carboxy-terminal portion of eIF4G, we originally expected that NAT1, like the carboxy-terminal fragment of eIF4G, would support the cap-independent translation initiation. Although the vast majority of cellular RNAs are capped and translated by the cap-dependent translation initiation, many examples of the cap-independent translation of cellular
RNAs have been reported recently (Teerink et al. 1995; Vagner et al. 1995; Gan and Rhoads 1996). NAT1 may be involved in the cap-independent translation initiation of certain cellular RNAs. Using the yeast two-hybrid system, we demonstrated that NAT1 binds eIF4A, but not eIF4E, which is consistent with the protein-protein interaction of the carboxy-terminal portion of eIF4G. However, the impact of the overexpression of NAT1 on the cap-independent translation is diametric to that of the carboxy-terminal fragment of eIF4G. NAT1 inhibited the cap-independent translation of luciferase in a bicistronic reporter gene when cotransfected into COS7 cells, whereas the carboxy-terminal fragment of eIF4G markedly enhanced the cap-independent translation. What is the mechanism for this apparent discrepancy between NAT1 and the carboxy-terminal fragment of eIF4G? One possibility is that NAT1 lacks some functional domains of the carboxy-terminal fragment and functions as a dominant-negative factor. Besides binding to eIF4A and eIF4E, eIF4G enhances the unwinding activity of eIF4A (Rozen et al. 1990) and binds to ribosomes via eIF3 (Lamphear et al. 1995) and to RNA (Jaramillo et al. 1991a). 
Because $\mathrm{p} 80$ associates with microtubules (Bokros et al. 1995), human eIF4G may also. It is likely that NAT1 lacks some of these essential functions of eIF4G. Thus, NAT1 acts as a dominant-negative repressor of the capindependent translation initiation.

In contrast to their opposite effects on cap-independent translation initiation, both NATl and the carboxyterminal portion of eIF4G inhibit cap-dependent translation. Because these two proteins bind eIF4A but not eIF4E (Fig. 5B) (Lamphear et al. 1995), they cannot support cap-dependent translation. Both NAT1 and the carboxy-terminal portion of eIF4G should compete with the intact eIF4G for the binding to eIF4A and thus exert a dominant-negative effect. That overexpression of NAT1 inhibits both cap-dependent and cap-independent translation suggests that NAT1 functions as a general translation repressor.

Recently, 4E-binding proteins (4E-BPs, also called PHAS-1) were identified as translational repressors that are regulated by insulin and other growth factors (Lin et al. 1994; Pause et al. 1994). NAT1 has similarities and differences with 4E-BPs (Fig. 6). Both compete with eIF4G for binding to other subunits of eIF4F and function as dominant-negative repressors of translation initiation. Although the 4E-BPs bind eIF4E, which is required only for the cap-dependent translation initiation, NAT1 binds eIF4A, which is essential for both cap-dependent and cap-independent translation initiation. Thus, 4E-BPs inhibit only cap-dependent translation initiation and have no effect on the cap-independent translation initiation (Pause et al. 1994), whereas NAT1 represses both types of translation initiation. Perhaps more important, the limited number of cellular mRNAs translated by the cap-independent mechanisms all encode proteins with important cellular functions, such as fibroblast growth factor 2 (Skrinska et al. 1988), insulin growth factor II (Teerink et al. 1995), and eIF4G (Gan and Rhoads 1996).

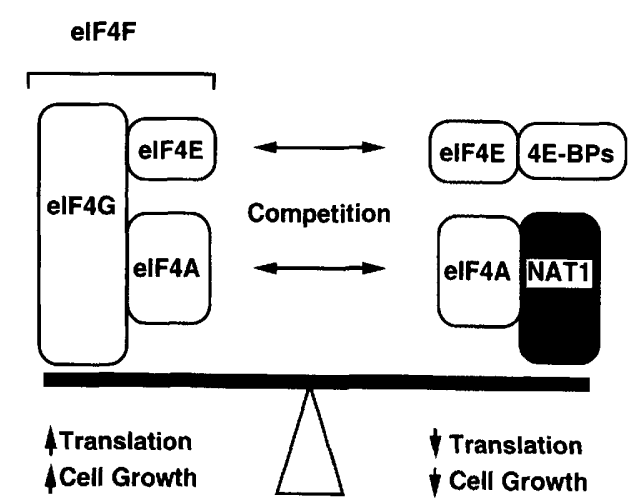

Figure 6. Illustration of NATl and 4E-binding proteins (4E$\mathrm{BPs}$ ) functioning as translation repressors. $4 \mathrm{E}-\mathrm{BP}$ compete with eIF4G for binding to eIF4E and repress cap-dependent translation. This competition is a determinant of translation and cell growth regulation. Overexpression of eIF4E transforms cells in culture, whereas overexpression of 4E-BPs inhibits cell growth. Our results suggest that NATI competes with eIF4G for binding to eIF4A and represses both cap-dependent and cap-independent translation.
Therefore, the repression of this type of translation by NAT1 may have a great impact. NAT1 and 4E-BPs also differ in tissue distribution. Each 4E-BP has its own tissue distribution pattern and each is absent or found at low levels in some tissues (Hu et al. 1994; Lin et al. 1994; Pause et al. 1994). In contrast, NAT1 exists at a high level in all tissues and cell lines examined. These observations, and the ubiquitous expression and the extraordinarily high conservation of NAT1 among species, suggest that NAT1 is a fundamental negative regulator of translation initiation in all mammalian cell types.

\section{Could hyperediting of NAT1 contribute to the potent oncogenesis by $A P O B E C-1$ ?}

Although we have not demonstrated the involvement of NAT1 in cell growth control, translation initiation is important in the regulation of cell growth and oncogenesis (Morris 1995; Sonenberg 1993). For example, the translation initiation factor eIF2 forms a ternary complex with tRNA ${ }^{\text {Met }}$ and GTP and is essential for the tRNA $^{\mathrm{Met}}$ binding to the $40 \mathrm{~S}$ ribosomal subunit (Hershey 1991; Merrick 1992; Rhoads 1993|. Phosphorylation of eIF2 by PKR (protein kinase RNA-dependent) inactivates eIF2 and decreases translation initiation. Expression of a dominant-negative mutant of PKR causes malignant transformation in NIH-3T3 cells (Koromilas et al. 1992; Lengyel 1993; Meurs et al. 1993). Furthermore, expression of a nonphosphorylatable mutant of eIF2 also caused transformation in NIH-3T3 cells (Donzé et al. 1995). These results clearly demonstrate the importance of translation control in regulating cell growth. As another example, overexpression of the cap-binding protein eIF4E up-regulated translation initiation, transformed NIH-3T3 and Rat 1 cells (Lazaris-Karatzas et al. 1990), and caused aberrant growth of HeLa cells (De Benedetti and Rhoads 1990). Furthermore, the concentration of eIF4E is elevated in cultured cells transformed by various mechanisms (Miyagi et al. 1995) as well as in human breast carcinomas (Kerekatte et al. 1995). In contrast, the 4E-BPs suppress translation initiation and cell growth (Lin et al. 1994; Pause et al. 1994). Overexpression of 4E-BP1 and 4E-BP2 in NIH-3T3 cells transformed by vras or v-src or by eIF4E partially reverts these cells to a nontransformed phenotype (Sonenberg 1996). The balance between proteins that enhance translation initiation, such as eIF4F, and proteins that repress translation initiation, such as 4E-BPs, is an important determinant of cell proliferation or, conversely, growth restrictive scenarios such as cell cycle arrest, terminal differentiation, and programmed cell death (Fig. 6) (Sonenberg 1993; Hentze 1995; Morris 1995). The disruption of this balance can lead to deregulated growth or oncogenesis. As a translation repressor, NAT1 could influence this balance. Therefore, it is feasible to postulate that the markedly reduced levels of NATl attributable to the hyperediting contribute to the potent oncogenesis mediated by APOBEC-1.

Several structural features of NAT1 mRNA support the notion that NAT1 is involved in regulating cell 
growth. These include relatively long $5^{\prime}$ and $3^{\prime}$ UTRs, an upstream open reading frame in the $5^{\prime}$ UTR, a non-AUG start codon, an AU-rich $3^{\prime}$ UTR, and an AUUUA destabilizing element in $3^{\prime}$ UTR. These features are often seen in mRNAs encoding growth-related proteins /Greenberg and Belasco 1993; Hann 1994) and are consistent with the role of NAT1 as a translation repressor involved in cell growth regulation.

\section{New insight into the mechanism of the} APOBEC-1-mediated RNA editing

The identification of NAT1 as the second major target of APOBEC-1-mediated mRNA editing in transgenic mice and rabbits also provides new insights into the mechanism of RNA editing. The mooring sequence is the sequence motif in apoB mRNA necessary and sufficient for reduced efficiency of editing when placed in the context of some, but not all, heterologous mRNAs (Boström et al. 1989; Shah et al. 1991; Backus and Smith 1994). Even though P1 protein mRNA and fatty acid synthase (FAS) mRNA contain the mooring sequence, they were not edited even in the livers of APOBEC-1 transgenic mice (Yamanaka et al. 1995) (Fig. 7). The lack of editing in P1 protein and FAS mRNA, which contain mooring-like sequences, suggests that other unidentified sequence/ structure element(s) are required for editing. Previously, we showed that multiple cytidines of apoB mRNA are edited in transgenic animal livers expressing APOBEC-1 and this hyperediting of apoB mRNA does not require the exact mooring sequence. We hypothesized that the hyperediting of apoB mRNA by overexpressed APOBEC-1 requires only mooring-like motifs (not the exact mooring sequence) (Yamanaka et al. 1996), whereas nor-

\section{A Normal Editing}

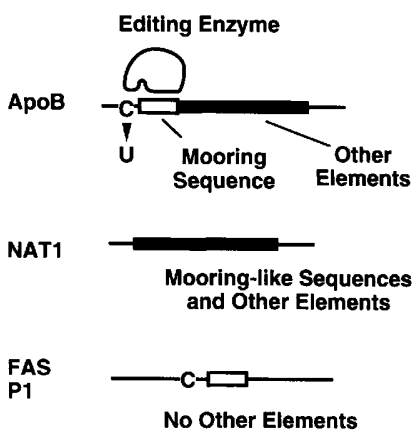

\section{B Hyperediting}

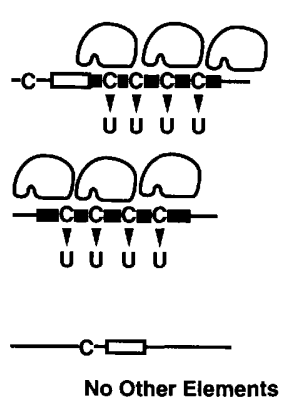

Figure 7. Putative sequence requirement for APOBEC-1-mediated mRNA editing. $(A)$ In normal animals, at least two elements, the mooring sequence and other unidentified elements, are required for editing. NATI lacks the exact mooring sequence, and P1 protein mRNA and FAS mRNA lack the other elements, and therefore none of these mRNAs can be edited in normal animals. $(B)$ When APOBEC-1 is overexpressed, the other elements become sufficient to support editing and lead to the hyperediting of apoB mRNA and NAT1. P1 and FAS that lack the other elements still cannot be edited. mal editing requires both the exact mooring sequence and the other sequence motifs (Backus and Smith 1994) (Fig. 7). The hyperediting of NAT1 is consistent with these previous results. Because NATl does not contain the exact mooring sequence, the hyperediting of NAT1, similar to that of apoB mRNA, seems to be achieved by a combination of mooring-like motifs and the other unidentified elements. Furthermore, although NAT1 is hyperedited in the liver of transgenic animals expressing APOBEC-1, it is not edited in the small intestine or liver of normal animals. We believe NATl cannot be edited in normal animals because it lacks the exact mooring sequence. What sequence or structural elements support hyperediting? NATl, especially its $3^{\prime}$ half where cytidines are preferentially edited, has many sequence and motif similarities to apoB mRNA. These include a cluster of mooring-like sequences, an AU-rich sequence, and a cluster of TGAT motifs. Further analysis of NAT1 and apoB mRNA sequences should elucidate the sequence requirements for APOBEC-1-mediated mRNA editing.

The important question of how many different mRNAs are modified by APOBEC-1-mediated editing is still unknown. In normal animals, the combination of the mooring sequence and the other sequence elements makes the editing reaction extremely specific, which results in the deamination of one cytidine $\left(\mathrm{C}^{6666}\right)$ of apoB mRNA. This may be the only target of normal apoB mRNA editing. The disruption of the apobec-1 gene in mice resulted in only slight alterations in lipid metabolism as a result of the loss of apoB48, the product of apoB mRNA editing, without any other significant phenotypic changes (Hirano et al. 1996; Morrison et al. 1996). Even in the apobec- 1 transgenic mice, all but one of the RNAs containing mooring or mooring-like sequences were unedited. Our modified differential display with 24 different arbitrary primers identified only a limited number of candidate bands. Theoretically, these 24 primers could detect all the mRNAs expressed in each cell (Liang and Pardee 1992). Thus, it appears that even hyperediting has a certain degree of specificity even though it lacks the precision of normal apoB mRNA editing. The limited number of differentially displayed candidate bands, together with the fact that NAT1 is hyperedited in both transgenic mice and rabbits, support the possible involvement of NAT1 hyperediting with the potent pathophysiological changes caused by the overexpression of APOBEC-1.

In conclusion, we have identified a novel translation repressor, NAT1. Overexpressed APOBEC-1 extensively edits NAT1 mRNA, and the effect in the apobec-1 transgenic animals is analogous to a liver-specific knockout of the NAT1 gene by homologous recombination. Aberrant editing of the translation repressor could contribute to the oncogenesis caused by the overexpressed APOBEC-1.

\section{Materials and methods}

Modified differential display

Total RNA was isolated from the livers of 7-month-old control and transgenic mice expressing APOBEC-1 (line I20) using Tri- 
zol reagent (Life Technologies). Differential display of total RNA from control and transgenic mouse livers was performed with the Differential Display kit (Display Systems) according to the manufacturer's protocol, except that mooring primers were used instead of anchored oligo(dT) primers for both first-strand cDNA synthesis and PCR. The mooring primers consist of the complementary sequence to the mooring sequence, three to five degenerative nucleotides, and an adenosine residue at the $3^{\prime}$ end. Edited mRNAs were expected to be amplified more effectively than unedited mRNAs because the uridine generated by the deamination of cytidine would base-pair with the adenosine at the $3^{\prime}$ end of the mooring primers. The modified differential display was performed with combinations of 24 different arbitrary 10-mer primers (sense primers) and the three different mooring primers (antisense primers). The PCR product was labeled with ${ }^{33} \mathrm{P}$, separated by polyacrylamide gel electrophoresis, and detected by autoradiography. DNA was eluted from differentially amplified bands, reamplified by ligation-mediated PCR, subcloned into pCRII vectors (Invitrogen), and sequenced by an automated fluorescence DNA sequencer (Applied Biosystems).

\section{Northern and Southern blot analyses}

For Northern blot analyses of NAT1, Human Multiple Tissue Northern (MTN) Blot, Human MTN Blot II, Human Fetal MTN Blot, Human Cancer Cell Line MTN Blot, and Mouse MTN Blot (Clontech) were hybridized with ${ }^{32} \mathrm{P}$-labeled human NAT1 cDNA. The blots were washed under stringent conditions $(0.1 \times \mathrm{SSC}, 0.1 \% \mathrm{SDS})$ at $65^{\circ} \mathrm{C}$ and were exposed to X-ray film at $-70^{\circ} \mathrm{C}$ with two intensifying screens for 2-6 hr. For Southern blot analysis of NAT1, ZOO-BLOT (Clontech) was hybridized, washed as described above, and was exposed to X-ray film at $-70^{\circ} \mathrm{C}$ with two intensifying screens for $15 \mathrm{hr}$.

\section{Cloning the full-length NAT1 cDNA}

We obtained a human EST clone (2.4 kb) corresponding to the $3^{\prime}$ portion of human NAT1 cDNA from the IMAGE Consortium. The sequence of the missing $5^{\prime}$ portion was obtained by four rounds of $5^{\prime}$-RACE-PCR, and a PCR primer was designed (U10, $5^{\prime}$-GAGTCGGAGCTCTATGGAGGTG-3') from its $5^{\prime}$ end. The full-length cDNA of human NAT1 was amplified by RTPCR using primers U10 and D45620-146LP $\left(5^{\prime}\right.$-TTTCAAGTATCACAATGTTTATTG- $\left.3^{\prime}\right)$ and was subcloned into pCRII vector. Multiple clones were sequenced, and a clone without any PCR-induced mutation was selected for further studies (pCRII-hNAT1). Mouse and rabbit NAT1 was amplified by RTPCR with the same primers and subcloned into PCRII vectors (pCRII-mNAT1 and pCRII-rNAT1).

\section{Primer extension analyses and in vitro editing assay}

To confirm the editing of NAT1, the 115-base fragment in the 3' UTR of the NATl sequence was amplified by PCR from rabbit and mouse genomic DNA, control liver cDNA, and transgenic liver cDNA with primers D45620-32UP $\left(5^{\prime}\right.$-GGTGTGAACAAATGGTGAGAAT-3') and D45620-146LP. PCR products were analyzed by primer extension using a primer PE85 (5'AGTGTGAGAATTTGAATTGGTCCC-3') for $\mathrm{C} \rightarrow \mathrm{U}$ editing (Yamanaka et al. 1995). To determine whether NAT1 can be edited in vitro, RNA was transcribed in vitro from the plasmid pCRII-mNAT1. In vitro editing and primer extension assays were performed as described previously (Yamanaka et al. 1996).
Site-directed mutagenesis and in vitro transcription and translation

Truncation and substitution mutants of NAT1 were generated by PCR. The upper PCR primers used were as follows: U11 (5'-GCTGCTGAGTTTCTCGGTGAAGGT-3') for $\Delta 199$, U12 $\left(5^{\prime}\right.$-СTCCCCTCCCCACCCCATCTATTA-3') for $\Delta 241$, U13 $\left(5^{\prime}\right.$ ' TTCTTCGTTTGCAAGCCGCCAAAG-3' $\mid$ for $\Delta 283$, U15wt (5'-CAAAGTGGAGAGTGCGATTGCAGA-3') for $\Delta 302$, U14 (5'-AAGGGGGTGCTTCTCGTTTCAGTG-3') for $\Delta 324$, U15T308A (5'-CAAAGAGGAGAGTGCGATTGCAGA-3') for GTG $\rightarrow$ GAG, and U15-A319T (5'-CAAAGTGGAGAGTGCGTTTGCAGA-3'\} for ATT $\rightarrow$ TTT. The lower primer used was L4 (5'-GCTTTGGCTGGTTCTTTAGT-3'). The mutant NAT1 sequences were amplified from pCRII-hNAT1 with these primers, subcloned into pCRII vectors, and expressed by in vitro transcription/translation with a TNT-coupled reticulocyte system (Promega) in the presence of $\left[{ }^{35} \mathrm{~S}\right]$ methionine. The translated products were separated by SDS-PAGE and detected by fluorography with Amplify (Amersham).

Generation of anti-NAT1 antibody and Western blot analysis

A BamHI-HindIII fragment of human NAT1 cDNA (380 bp) was subcloned into pQE30 vector (Qiagen) and transformed into Escherichia coli (strain BL21) to produce a $6 \times$ histidine-tagged polypeptide of NAT1 (corresponding to amino acids 369-490). The induction and purification with a nickel resin column were performed under denaturing conditions according to the manufacturer's protocol. The purified polypeptide was injected into New Zealand White rabbits to produce an anti-NAT1 polyclonal antibody. Western blotting was performed with ECL (Amersham). The standard conditions were as follows: liver extract, 50-100 $\mu$; primary antibody (anti-NAT1), 1:5000-10000 dilution; secondary antibody (horseradish peroxidase-conjugated anti-rabbit $\operatorname{IgG}$ ), 1:10000 dilution.

\section{Yeast two-hybrid system}

The Matchmaker Two-Hybrid System (Clontech) was used to study protein-protein interaction of NAT1. The coding regions of the mouse eIF4A and eIF4E were obtained by RT-PCR from mouse liver RNA with primers M4AU2 (5'-GGAGCCGGAAGGCGTCATCG-3') and M4AL2 (5'-GCAGGACAGCCCCTCAAATG-3' $\}$ for eIF4A, and M4EU2 $\left\{5^{\prime}\right.$-TAAGATGGCGACTGTGGAAC-3') and M4EL2 (5'-GTCTTCTTAAACAACAAACC-3') for eIF4E and subcloned into pCRII vector (pCRII-m4A and pCRII-m4E). EcoRI fragments of pCRII-m4A and pCRII$\mathrm{m} 4 \mathrm{E}$ were subcloned into pGAD424 plasmids (Clontech) to generate fusion proteins with the GAL4 activation domain (pGAD424-4A and pGAD424-4E, respectively). An EcoRI fragment of pCRII-mNAT1 was subcloned into a pGBT9 plasmid to generate a fusion protein with the DNA-binding domain of the GAL4 transcription activator (pGBT9-NAT1). pGBT9-NAT1 was cotransformed with either pGAD424, pGAD424-4A, or pGAD424-4E into yeast (Saccharomyces cerevisae SDF526), and $\beta$-galactosidase activity was determined by a filter assay or a liquid culture assay according to the manufacturer's protocol.

\section{Transient transfections into COS7 cells}

An EcoRI fragment of human NAT1 cDNA from pCRII-hNAT1 was subcloned into pcDNA3.1 to produce pcDNA-hNAT1 for the mammalian expression of NAT1. The carboxy-terminal two-thirds of human eIF4G (corresponding to amino acids $477-$ 1396) was obtained by RT-PCR from mouse liver total RNA 
with primers 4GU4 $\left\{5^{\prime}\right.$-ACCCTTGGCCGGACAACCCTTAGCAC- $\left.3^{\prime}\right)$ and 4GL1 (5' -CATCACACTACAGGCACCCACTGC$\left.3^{\prime}\right)$ and subcloned into pFlag-CMV2 to produce pFlag-m4G(C) for the mammalian expression of the carboxy-terminal fragment of eIF4G. A NcoI-BamHI fragment of luciferase cDNA from pGL3-Basic (Promega) was subcloned into pCITE4(a) (Novagen) to produce pIRES-Luc. A fragment containing IRES and the luciferase-coding region was amplified by PCR with primers CITE-U-XbaI (5'-TGCTCTAGAGTTATTTTCCACCATATTGC-3' $)$ and CITE-L-XbaI (5'-TGCTCTAGATATCATCGTGTTTTTCAAAG-3') from the pIRES-Luc, digested with $X b a I$, and subcloned into an $\mathrm{XbaI}$ site of pcDNA3.1-CAT to produce pCAT-IRES-LUC for the expression of a bicistronic reporter gene. COS7 cells were cultured in Dulbecco's modified Eagle medium containing $10 \%$ fetal bovine serum in a $7 \% \mathrm{CO}_{2}$ incubator. For transient transfection, $1 \times 10^{5}$ cells were plated into six-well plates $24 \mathrm{hr}$ before transfection. pCAT-IRES-Luc 10.5 $\mu \mathrm{g})$ was cotransfected with either pcDNA3.1, pFlag-4G(C), or pcDNA-hNAT1 (1.5 $\mu$ g each) by TransIT-LT2 (Panvera) according to the manufacturer's protocol. We used $2 \mu \mathrm{l}$ of TransITLT2 for every $1 \mu \mathrm{g}$ of DNA and incubated cells with DNAliposome complex for $4 \mathrm{hr}$ in serum-free medium. After $4 \mathrm{hr}$, the medium was replaced with complete medium. Seventytwo hours later, luciferase and CAT activity in cell extracts were measured with a luciferase assay kit and a CAT ELISA kit (Boehringer Mannheim), respectively. Total RNA was isolated from separate wells and analyzed by Northern blot with a ${ }^{32} \mathrm{P}$ labeled 2-kb DNA probe containing IRES and luciferase to measure the mRNA level of the reporter gene.

\section{Fluorescence in situ hybridization}

A P1 clone containing the human NAT1 gene was obtained from Genome Systems. Purified DNA from this P1 clone was labeled with digoxigenin dUTP by nick translation. Labeled probe was combined with sheared human DNA and hybridized to normal metaphase chromosomes derived from phytohemagglutinin-stimulated peripheral blood lymphocytes in a solution containing $50 \%$ formamide, $10 \%$ dextran sulfate, and $2 \times$ SSC. Specific hybridization signals were detected by incubating the hybridized slides with fluorescein-conjugated anti-digoxigenin antibodies followed by counterstaining with propidium iodide. The initial experiment resulted in specific labeling of the long arm of a group $\mathrm{C}$ chromosome. A second experiment was conducted in which a chromosome 11 centromere-specific probe (D11Z1) was cohybridized with the labeled P1 DNA. This experiment resulted in the specific labeling of the centromere and the short arm of chromosome 11. Measurements of 10 different examples of chromosome 11 demonstrated that the NAT1 gene is located at a position that is $68 \%$ of the distance from the centromere to the telomere of chromosome arm $11 \mathrm{p}$, an area that corresponds to the proximal portion of band $11 \mathrm{p} 15$. Of 80 metaphase cells analyzed, 74 exhibited specific labeling.

\section{Acknowledgments}

We thank Dr. Martin Hersberger for helpful discussions; Drs. Robert Mahley, Robert Farese, Jr., Stanley Rall, and Karl Weisgraber for critical comments on this manuscript; Amy Corder, Brian Clark, Stephen Gonzales, and John Carroll for graphics; Susannah White and Don Haumant for manuscript preparation; Stephen Ordway and Gary Howard for editorial support; and Jenny Karr for DNA sequencing. This work was supported in part by funds from the National Institutes of Health /grant HL47660|
The publication costs of this article were defrayed in part by payment of page charges. This article must therefore be hereby marked "advertisement" in accordance with 18 USC section 1734 solely to indicate this fact.

\section{Note added in proof}

The accession numbers for NAT-1 are U76111 for human NAT1, U76112 for mouse NAT-1, and U76113 for rabbit NAT-1.

\section{References}

Adams, M.D., M. Dubnick, A.R. Kerlavage, R. Moreno, J.M. Kelley, T.R. Utterback, J.W. Nagle, C. Fields, and J.C. Venter. 1992. Sequence identification of 2,375 human brain genes. Nature. 355: 632-634.

Allen, M.L., A.M. Metz, R.T. Timmer, R.E. Rhoads, and K.S. Browning. 1992. Isolation and sequence of the cDNAs encoding the subunits of the isozyme form of wheat protein synthesis initiation factor 4F. J. Biol. Chem. 267: 2323223236.

Altschul, S.F., W. Gish, W. Miller, E.W. Myers, and D.J. Lipman. 1990. Basic local alignment search tool. I. Mol. Biol. 215: 403-410.

Anant, S., A.J. MacGinnitie, and N.O. Davidson. 1995. apobec1 , the catalytic subunit of the mammalian apolipoprotein $B$ mRNA editing enzyme, is a novel RNA-binding protein. $J$. Biol. Chem. 270: 14762-14767.

Backus, J.W. and H.C. Smith. 1994. Specific 3' sequences flanking a minimal apolipoprotein $\mathrm{B}$ (apoB) mRNA editing "cassette $^{\prime \prime}$ are critical for efficient editing in vitro. Biochim. Biophys. Acta. 1217: 65-73.

Backus, J.W., D. Schock, and H.C. Smith. 1994. Only cytidines $5^{\prime}$ of the apolipoprotein B mRNA mooring sequence are edited. Biochim. Biophys. Acta. 1219: 1-14.

Bokros, C.L., J.D. Hugdahl, H.-H. Kim, V.R. Hanesworth, A. van Heerden, K.S. Browning, and L.C. Morejohn. 1995. Function of the p86 subunit of eukaryotic initiation factor (iso) $4 \mathrm{~F}$ as a microtubule-associated protein in plant cells. Proc. Natl. Acad. Sci. 92: 7120-7124.

Boström, K., S.J. Lauer, K.S. Poksay, Z. Garcia, J.M. Taylor, and T.L. Innerarity. 1989. Apolipoprotein B48 RNA editing in chimeric apolipoprotein EB mRNA. I. Biol. Chem. 264: 15701-15708.

Chen, S.-H., G. Habib, C.-Y. Yang, Z.-W. Gu, B.R. Lee, S.-A. Weng, S.R. Silberman, S.-J. Cai, J.P. Deslypere, M. Rosseneu, A.M. Gotto, Jr., W.-H. Li, and L. Chan. 1987. Apolipoprotein B-48 is the product of a messenger RNA with an organ-specific in-frame stop codon. Science 238: 363-366.

De Benedetti, A. and R.E. Rhoads. 1990. Overexpression of eukaryotic protein synthesis initiation factor $4 \mathrm{E}$ in HeLa cells results in aberrant growth and morphology. Proc. Natl. Acad. Sci. 87: 8212-8216.

Donzé, O., R. Jagus, A.E. Koromilas, J.W.B. Hershey, and N. Sonenberg. 1995. Abrogation of translation initiation factor eIF-2 phosphorylation causes malignant transformation of NIH 3T3 cells. EMBO T. 14: 3828-3834.

Driscoll, D.M. and Q. Zhang. 1994. Expression and characterization of $\mathrm{p} 27$, the catalytic subunit of the apolipoprotein B mRNA editing enzyme. T. Biol. Chem. 269: 19843-19847.

Driscoll, D.M., S. Lakhe-Reddy, L.M. Oleksa, and D. Martinez. 1993. Induction of RNA editing at heterologous sites by se- 
quences in apolipoprotein B mRNA. Mol. Cell. Biol. 13: $7288-7294$.

Frohman, M.A., M.K. Dush, and G.R. Martin. 1988. Rapid production of full-length cDNAs from rare transcripts: Amplification using a single gene-specific oligonucleotide primer. Proc. Nat1. Acad. Sci. 85: 8998-9002.

Gan, W. and R.E. Rhoads. 1996. Internal initiation of translation directed by the $5^{\prime}$-untranslated region of the mRNA for eIF4G, a factor involved in the picornavirus-induced switch from cap-dependent to internal initiation. I. Biol. Chem. 271: 623-626.

Giannoni, F., D.K. Bonen, T. Funahashi, C. Hadiiagapiou, C.F. Burant, and N.O. Davidson. 1994. Complementation of apolipoprotein B mRNA editing by human liver accompanied by secretion of apolipoprotein B48. I. Biol. Chem. 269: 59325936.

Goyer, C., M. Altmann, H.S. Lee, A. Blanc, M. Deshmukh, J.L. Woolford, Jr., H. Trachsel, and N. Sonenberg. 1993. TIF4631 and TIF4632: Two yeast genes encoding the high-molecularweight subunits of the cap-binding protein complex (eukaryotic initiation factor $4 \mathrm{~F}$ ) contain an RNA recognition motiflike sequence and carry out an essential function. Mol. Cell. Biol. 13: 4860-4874.

Greenberg, M.E. and J.G. Belasco. 1993. Control of the decay of labile protooncogene and cytokine mRNAs. In Control of messenger RNA stability (ed. J.G. Belasco and G. Brawerman), pp. 199-218. Academic Press, San Diego, CA.

Greeve, J., I. Altkemper, J.-H. Dieterich, H. Greten, and E. Windler. 1993. Apolipoprotein B mRNA editing in 12 different mammalian species: Hepatic expression is reflected in low concentrations of apoB-containing plasma lipoproteins. $I$. Lipid Res. 34: 1367-1383.

Hann, S.R. 1994. Regulation and function of non-AUG-initiated proto-oncogenes. Biochimie 76: 880-886.

Harris, S.G., I. Sabio, E. Mayer, M.F. Steinberg, J.W. Backus, J.D. Sparks, C.E. Sparks, and H.C. Smith. 1993. Extract-specific heterogeneity in high-order complexes containing apolipoprotein B mRNA editing activity and RNA-binding proteins. J. Biol. Chem. 268: 7382-7392.

Hentze, M.W. 1995. Translational regulation: Versatile mechanisms for metabolic and developmental control. Curr. Opin. Cell Biol. 7: 393-398.

Hershey, J.W.B. 1991. Translational control in mammalian cells. Annu. Rev. Biochem. 60: 717-755.

Hirano, K.-I., S.G. Young, R.V. Farese, Jr., J. Ng, E. Sande, C. Warburton, L.M. Powell-Braxton, and N.O. Davidson. 1996. Targeted disruption of the mouse apobec-1 gene abolishes apolipoprotein B mRNA editing and eliminates apolipoprotein B48. J. Biol. Chem. 271: 9887-9890.

Hu, C., S. Pang, X. Kong, M. Velleca, and J.C. Lawrence, Jr. 1994. Molecular cloning and tissue distribution of PHAS-I, an intracellular target for insulin and growth factors. Proc. Natl. Acad. Sci. 91: 3730-3734.

Innerarity, T.L., J. Borén, S. Yamanaka, and S.-O. Olofsson. 1996. Biosynthesis of apolipoprotein B48-containing lipoproteins. Regulation by novel post-transcriptional mechanisms. J. Biol. Chem. 271: 2353-2356.

Jaramillo, M., T.E. Dever, W.C. Merrick, and N. Sonenberg. 1991a. RNA unwinding in translation: Assembly of helicase complex intermediates comprising eukaryotic initiation factors eIF-4F and eIF-4B. Mol. Cell. Biol. 11: 5992-5997.

Jaramillo, M., J. Pelletier, I. Edery, P.J. Nielsen, and N. Sonenberg. 1991b. Multiple mRNAs encode the murine translation initiation factor eIF-4E. J. Biol. Chem. 266: 1044610451.

Kerekatte, V., K. Smiley, B. Hu, A. Smith, F. Gelder, and A. De
Benedetti. 1995. The proto-oncogene/translation factor eIF4E: A survey of its expression in breast carcinomas. Int. J. Cancer. 64: 27-31.

Koromilas, A.E., S. Roy, G.N. Barber, M.G. Katze, and N. Sonenberg. 1992. Malignant transformation by a mutant of the IFN-inducible dsRNA-dependent protein kinase. Science 257: 1685-1689.

Kozak, M. 1991. An analysis of vertebrate mRNA sequences: Intimations of translational control. J. Cell Biol. 115: 887903.

Lamphear, B.J., R. Yan, F. Yang, D. Waters, H.-D. Liebig, H. Klump, E. Kuechler, T. Skern, and R.E. Rhoads. 1993. Mapping the cleavage site in protein synthesis initiation factor eIF- $4 \gamma$ of the $2 \mathrm{~A}$ proteases from human Coxsackievirus and rhinovirus. I. Biol. Chem. 268: 19200-19203.

Lamphear, B.J., R. Kirchweger, T. Skern, and R.E. Rhoads. 1995. Mapping of functional domains in eukaryotic protein synthesis initiation factor $4 \mathrm{G}$ (eIF4G) with picornaviral proteases. Implications for cap-dependent and cap-independent translational initiation. J. Biol. Chem. 270: 21975-21983.

Lazaris-Karatzas, A., K.S. Montine, and N. Sonenberg. 1990. Malignant transformation by a eukaryotic initiation factor subunit that binds to mRNA $5^{\prime}$ cap. Nature 345: 544-547.

Lengyel, P. 1993. Tumor-suppressor genes: News about the in terferon connection. Proc. Natl. Acad. Sci. 90: 5893-5895.

Liang, P. and A.B. Pardee. 1992. Differential display of eukaryotic messenger RNA by means of the polymerase chain reaction. Science 257: 967-971.

Lin, T.-A., X. Kong, T.A.J. Haystead, A. Pause, G. Belsham, N. Sonenberg, and J.C. Lawrence, Jr. 1994. PHAS-I as a link between mitogen-activated protein kinase and translation initiation. Science 266: 653-656.

Mader, S., H. Lee, A. Pause, and N. Sonenberg. 1995. The translation initiation factor eIF-4E binds to a common motif shared by the translation factor eIF- $4 \gamma$ and the translational repressors 4E-binding proteins. Mol. Cell. Biol. 15: 49904997.

Mano, H., F. Ishikawa, J. Nishida, H. Hirai, and F. Takaku. 1990. A novel protein-tyrosine kinase, tec, is preferentially expressed in liver. Oncogene 5: 1781-1786.

Merrick, W.C. 1992. Mechanism and regulation of eukaryotic protein synthesis. Microbiol. Rev. 56: 291-315.

Meurs, E.F., J. Galabru, G.N. Barber, M.G. Katze, and A.G. Hovanessian. 1993. Tumor suppressor function of the interferon-induced double-stranded RNA-activated protein kinase. Proc. Natl. Acad. Sci. 90: 232-236.

Miyagi, Y., A. Sugiyama, A. Asai, T. Okazaki, Y. Kuchino, and S.J. Kerr. 1995. Elevated levels of eukaryotic translation initiation factor eIF-4E, mRNA in a broad spectrum of transformed cell lines. Cancer Lett. 91: 247-252.

Morris, D.R. 1995. Growth control of translation in mammalian cells. Prog. Nucleic Acid Res. Mol. Biol. 51: 339-363.

Morrison, J.R., C. Pászty, M.E. Stevens, S.D. Hughes, T. Forte, J. Scott, and E.M. Rubin. 1996. Apolipoprotein B RNA editing enzyme-deficient mice are viable despite alterations in lipoprotein metabolism. Proc. Nat1. Acad. Sci. 93: 7154-7159.

Navaratnam, N., J.R. Morrison, S. Bhattacharya, D. Patel, T Funahashi, F. Giannoni, B.-B. Teng, N.O. Davidson, and J. Scott. 1993. The p27 catalytic subunit of the apolipoprotein B mRNA editing enzyme is a cytidine deaminase. J. Biol. Chem. 268: 20709-20712.

Navaratnam, N., S. Bhattacharya, T. Fujino, D. Patel, A.L. Jarmuz, and J. Scott. 1995. Evolutionary origins of apoB mRNA editing: Catalysis by a cytidine deaminase that has acquired a novel RNA-binding motif at its active site. Cell 81: 187195. 
Nielsen, P.J., G.K. McMaster, and H. Trachsel. 1985. Cloning of eukaryotic protein synthesis initiation factor genes: Isolation and characterization of cDNA clones encoding factor eIF-4A. Nucleic Acids Res. 13: 6867-6880.

Ohlmann, T., M. Rau, V.M. Pain, and S.J. Morley. 1996. The C-terminal domain of eukaryotic protein synthesis initiation factor (eIF) 4G is sufficient to support cap-independent translation in the absence of eIF4E. EMBO 7. 15: 1371-1382.

Pause, A., G.J. Belsham, A.-C. Gingras, O. Donzé, T.-A. Lin, J.C. Lawrence, Jr., and N. Sonenberg. 1994. Insulin-dependent stimulation of protein synthesis by phosphorylation of a regulator of $5^{\prime}$-cap function. Nature 371: 762-767.

Powell, L.M., S.C. Wallis, R.J. Pease, Y.H. Edwards, T.J. Knott, and J. Scott. 1987. A novel form of tissue-specific RNA processing produces apolipoprotein-B48 in intestine. Cell 50: $831-840$.

Rhoads, R.E. 1993. Regulation of eukaryotic protein synthesis by initiation factors. J. Biol. Chem. 268: 3017-3020.

Rozen, F., I. Edery, K. Meerovitch, T.E. Dever, W.C. Merrick, and N. Sonenberg. 1990. Bidirectional RNA helicase activity of eucaryotic translation initiation factors $4 \mathrm{~A}$ and $4 \mathrm{~F}$. Mol. Cell. Biol. 10: 1134-1144.

Scott, J. 1995. A place in the world for RNA editing. Cell 81: 833-836.

Shah, R.R., T.J. Knott, J.E. Legros, N. Navaratnam, J.C. Greeve, and J. Scott. 1991. Sequence requirements for the editing of apolipoprotein B mRNA. J. Biol. Chem. 266: 16301-16304.

Skrinska, V.A., M. Konieczkowski, R.G. Gerrity, C.F. Galang, and M.V. Rebec. 1988. Suppression of foam cell lesions in hypercholesterolemic rabbits by inhibition of thromboxane $\mathrm{A}_{2}$ synthesis. Arteriosclerosis 8: 359-367.

Sonenberg, N. 1993. Translation factors as effectors of cell growth and tumorigenesis. Curr. Opin. Cell Biol. 5: 955960.

-1996. mRNA 5' cap-binding protein eIF4E and control of cell growth. In Translational control (ed. J.W.B. Hershey, M.B. Mathews, and N. Sonenberg), pp. 245-269. Cold Spring Harbor Laboratory Press, Cold Spring Harbor, NY.

Teerink, H., H.O. Voorma, and A.A.M. Thomas. 1995. The human insulin-like growth factor II leader 1 contains an internal ribosomal entry site. Biochim. Biophys. Acta. 1264: 403408.

Teng, B., C.F. Burant, and N.O. Davidson. 1993. Molecular cloning of an apolipoprotein B messenger RNA editing protein. Science 260: 1816-1819.

Thach, R.E. 1992. Cap recap: The involvement of eIF-4F in regulating gene expression. Cell 68: 177-180.

Vagner, S., M.-C. Gensac, A. Maret, F. Bayard, F. Amalric, H. Prats, and A.-C. Prats. 1995. Alternative translation of human fibroblast growth factor 2 mRNA occurs by internal entry of ribosomes. Mol. Cell. Biol. 15: 35-44.

Yamanaka, S., K.S. Poksay, M.E. Balestra, G.-Q. Zeng, and T.L. Innerarity. 1994. Cloning and mutagenesis of the rabbit apoB mRNA editing protein. A zinc motif is essential for catalytic activity, and noncatalytic auxiliary factor(s) of the editing complex are widely distributed. J. Biol. Chem. 269: 2172521734.

Yamanaka, S., M.E. Balestra, L.D. Ferrell, J. Fan, K.S. Arnold, S. Taylor, J.M. Taylor, and T.L. Innerarity. 1995. Apolipoprotein B mRNA-editing protein induces hepatocellular carcinoma and dysplasia in transgenic animals. Proc. Natl. Acad. Sci. 92: 8483-8487.

Yamanaka, S., K.S. Poksay, D.M. Driscoll, and T.L. Innerarity. 1996. Hyperediting of multiple cytidines of apolipoprotein B mRNA by APOBEC-1 requires auxiliary protein(s) but not a mooring sequence motif. J. Biol. Chem. 271: 11506-11510.
Yan, R. and R.E. Rhoads. 1995. Human protein synthesis initiation factor eIF-4 $\gamma$ is encoded by a single gene (EIF4G) that maps to chromosome 3q27-qter. Genomics 26: 394-398.

Yan, R., W. Rychlik, D. Etchison, and R.E. Rhoads. 1992. Amino acid sequence of the human protein synthesis initiation factor eIF-4y. J. Biol. Chem. 267: 23226-23231. 


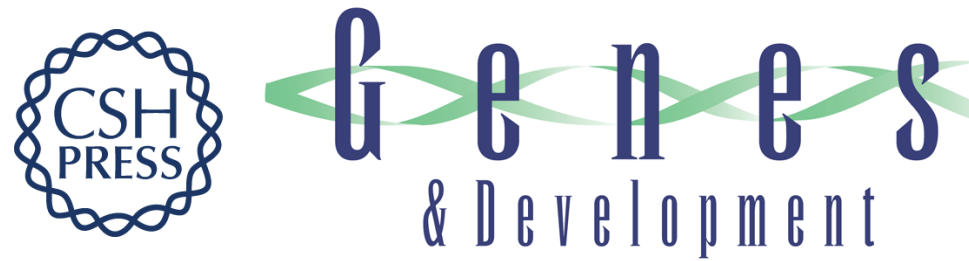

\section{A novel translational repressor mRNA is edited extensively in livers containing tumors caused by the transgene expression of the apoB mRNA-editing enzyme.}

S Yamanaka, K S Poksay, K S Arnold, et al.

Genes Dev. 1997, 11:

Access the most recent version at doi:10.1101/gad.11.3.321

References This article cites 64 articles, 41 of which can be accessed free at: http://genesdev.cshlp.org/content/11/3/321.full.html\#ref-list-1

License

Email Alerting Service

Receive free email alerts when new articles cite this article - sign up in the box at the top right corner of the article or click here.

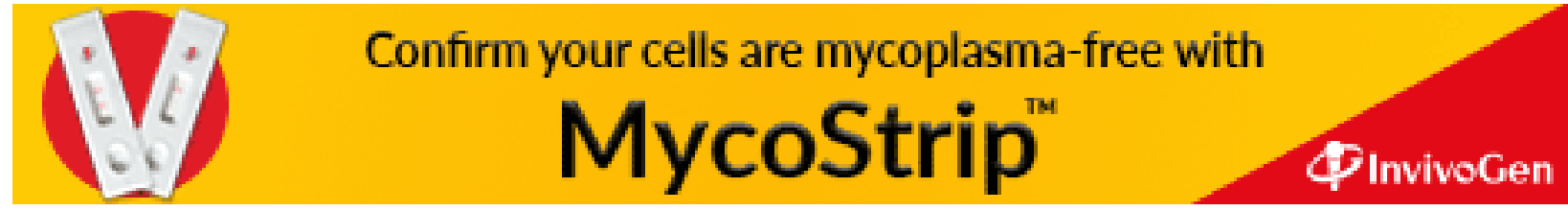

